\title{
Comparison of two different techniques of uterine closure in caesarean section: Continuous single layer technique versus Babu and Magon technique
}

\author{
Vinayachandran S., Vedhapriya Sudhakar*
}

Department of Obstetrics and Gynecology, IMCH, Government Medical College, Kozhikode, Kerala, India

Received: 24 April 2018

Accepted: 17 May 2018

\section{*Correspondence:}

Dr. Vedhapriya Sudhakar,

E-mail: vedh89@gmail.com

Copyright: (C) the author(s), publisher and licensee Medip Academy. This is an open-access article distributed under the terms of the Creative Commons Attribution Non-Commercial License, which permits unrestricted non-commercial use, distribution, and reproduction in any medium, provided the original work is properly cited.

\begin{abstract}
Background: To compare size of the caesarean scar and residual myometrial thickness (RMT) between continuous single non-interlocking and Babu and Magon technique for uterine closure following primary elective caesarean section (CS).

Methods: An observational prospective cohort study was conducted at 6 weeks and 4 months postpartum following primary elective CS. Group A included 25 patients who underwent continuous single layer technique and Group B included 25 patients who underwent Babu and Magon technique for uterine closure. Baseline demographic profile, obstetric score, details of the CS and associated complications were studied. Two-dimensional Transvaginal ultrasonography (TVS) measurements of the length, width and depth of the caesarean scar and RMT were compared.

Results: Mean age of study population was 29.6 years. Malpresentation (44\%) was the most common indication for CS. Mean Bishops score at the time of CS was $<4$. The duration of surgery ( $-2.8 \mathrm{~min}, 37.96 \pm 5.660 \mathrm{~min})$ and estimated amount of blood loss $(-51.6 \mathrm{ml}$, mean $671.20 \pm 136.208 \mathrm{ml})$ was less in Group A compared to Group B (40.76 $\pm 4.68 \mathrm{~min}, 722.80 \pm 132.083 \mathrm{ml}$ respectively). The caesarean scar measurements were similar in both groups at both visits. The mean RMT in Group B at 6 weeks and 4 months postpartum $(8.05 \mathrm{~mm} \pm 2.06$ and $7.10 \mathrm{~mm} \pm 2.04$ respectively) was statistically higher than Group A $(6.23 \mathrm{~mm} \pm 1.76$ and $5.36 \mathrm{~mm} \pm 1.70$ respectively $), \mathrm{p}=0.002$.

Conclusions: We conclude that Babu and Magon technique for uterine closure in caesarean section could result in better healing of the scar and probably reduce the adverse outcomes in subsequent pregnancies.
\end{abstract}

Keywords: Caesarean section, Residual myometrial thickness, Scar, Transvaginal ultrasound, Uterine closure

\section{INTRODUCTION}

Caesarean section is the most commonly performed surgery in the field of obstetrics. The rate of CS has been constantly increasing in the last few decades. The cause of increasing CS has been attributed to many factors like delivering a healthy baby and giving importance to maternal health. The technique of performing CS varies among many obstetricians. Through this surgery the mother is having a scar in her uterus which leads to various complications in a long run, important being uterine rupture and placenta accreta. This risk of uterine rupture is the main reason for decreasing rate of vaginal birth after CS and increasing rates of repeat CS.

Uterine closure is the most important step in CS. The aim is to reduce the morbidity and mortality of both current and future pregnancy. Cochrane database 2008 
gives substantial information regarding each step of caesarean and various techniques employed in those steps. ${ }^{1}$ Babu and Magon in their article proposed a new technique off uterine closure as they were of the view that in the existing techniques of uterine closure, correct approximation of the cut margins: decidua-to-decidua, myometrium to myometrium, serosa to serosa, were not guaranteed and that might be possibly due to edges getting overlapped; and so after remodelling and the process of healing, thickness of the site of lower segment caesarean section (LSCS) is significantly reduced. ${ }^{2}$

Thus they suggested a continuous modified mattress suture technique that could give a correct approximation of the cut margins. This study was done to compare scar parameters and RMT by TVS at 6 weeks and 4 months postpartum between Continuous single non-interlocking suture technique and Babu and Magon technique for uterine closure.

\section{METHODS}

A prospective Cohort study was conducted in the Institute of Maternal and Child Health, Kozhikode from Jan 2015 to June 2016. The study was approved by the Institutional Ethics Committee.

Patients above 18 years with singleton pregnancy after 38 completed weeks of gestation, who underwent primary lower segment caesarean section (LSCS), were included in the study. CS done in previously scarred uterus, in active phase of labor were excluded from the study.

After getting informed consent, 50 operated cases of LSCS were taken and grouped according to uterotomy closure done by the same surgeon. 25 patients in which uterine closure was done by continuous non-interlocking single layer technique (Group A) were chosen and assessed with TVS to measure the scar parameters and the same compared with equal number of patients in whom uterine closure was done by Babu and Magon technique (Group B). All the scans were done by the same radiologist to avoid bias based on standard technique and the nature of suturing technique was blinded to radiologist.

Baseline demographic data was collected based on the pre-formed proforma. Obstetric score, number of previous vaginal delivery if any, indication for $\mathrm{CS}$, Bishops score at the time of CS, and birth weight of the baby were noted.

The duration of surgery, estimated amount of blood loss, haemostatic sutures if applied, and any other intraoperative complications were considered. Postpartum transvaginal ultrasound was done at 6 weeks in order to rule out early scar defect and at 4months to assess the residual myometrial thickness and size of scar. TVS was performed in Radiology department using Mindray DC7 V10-4 of frequency 4-10 MHz.
Statistical analysis was done using SPSS 18.0 for windows. Qualitative data was expressed as frequency and percentage and quantitative data as mean and standard deviation (SD). Qualitative data was analysed by chi square test and Fisher's exact test and quantitative data by Student's t test.

\section{RESULTS}

64 cases of LSCS performed in the Institute of Maternal and Child Health, Kozhikode were studied during the period of January 2015 to June 2016. In 35 cases, uterus was closed with continuous non interrupted single layer and rest 29 cases with Babu and Magon technique. 14 were lost to follow-up in the post-partum visit. The final number of cases satisfied the required sample size. (Figure 1).

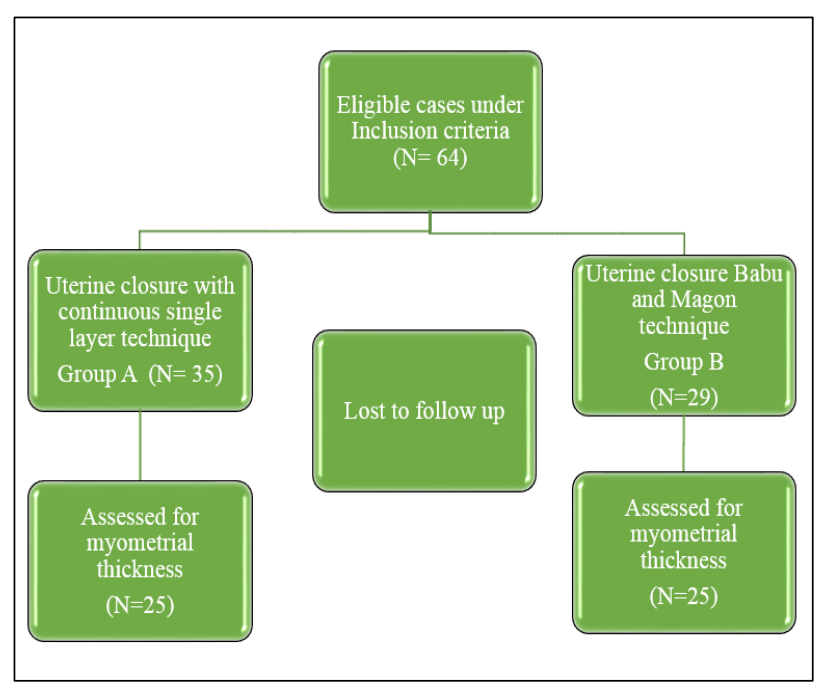

Figure 1: Selection of cases.

The mean age group of the study population was 29.6 years. Majority were less than 35 years $(82 \%)$. The present study included $60 \%$ multipara, among them $26 \%$ had previous vaginal birth.

$46 \%$ of the study group had antenatal complications. The most common complication was Gestational Diabetes Mellitus (30\%) followed by Gestational hypertension $(12 \%)$. The most common indication for elective caesarean section was Malpresentation (44\%) followed by Cephalopelvic disproportion (16\%). The other causes included IUGR with Abnormal Doppler, Elderly primigravida, prolonged period of infertility following IUI conception, presumed foetal jeopardy and recurrent pregnancy loss.

The mean Bishops score was less than 4 in both groups. Though the duration of surgery was comparatively less in Group A compared to Group B, it was not statistically significant $(p=0.06)$. Mean birth weight of babies of patients in group A was $3 \mathrm{~kg}$ with SD 0.53 and that of patients in group B was $2.89 \mathrm{~kg}$ with SD 0.52 . There was 
no significant difference in average birth weight of babies in the two groups, $\mathrm{p}=0.458$

The mean amount of blood loss in Group A was $671.2 \mathrm{ml}$ with $\mathrm{SD}=136.2$ and in Group B it was more amounting to $722 \mathrm{ml}$ with a $\mathrm{SD}=132.2$. But it was not statistically significant $(\mathrm{p}=0.18) .4$ cases among 25 people in Group A $(16 \%)$ required additional haemostatic sutures compared to one case in Group B (4\%). Only one case in (4\%) each group had post-partum haemorrhage and postoperative wound infection of the skin and subcutaneous layer. Uterus was anteverted in $66 \%$ of cases. The scar parameters noted in Group A at 6weeks were mean length $=8.17 \pm 1.76 \mathrm{~mm}$, mean width $=$ $4.30 \pm 0.98 \mathrm{~mm}$, mean depth $=3.32 \pm 0.86 \mathrm{~mm}$. At 4 months, the values were mean length $=7.15 \pm 1.44 \mathrm{~mm}$, mean width $=3.62 \pm 0.97 \mathrm{~mm}$, mean depth $=2.72 \pm 0.86 \mathrm{~mm}$. The mean residual myometrial thickness measured at 6weeks and 4 months was $6.23 \pm 1.76 \mathrm{~mm} 5.36 \pm 1.70 \mathrm{~mm}$ respectively (Table 1,2).

Table 1: Analysis of comparison of scar parameters-6 weeks.

\begin{tabular}{|c|c|c|c|c|c|c|}
\hline 6 weeks & Technique & $\mathbf{N}$ & Mean & SD & $\mathrm{t}$ & $\mathbf{p}$ \\
\hline \multirow{2}{*}{ Length of scar } & Single & 25 & 8.17 & 1.76 & \multirow{2}{*}{0.070} & \multirow{2}{*}{0.944} \\
\hline & $\mathrm{BM}$ & 25 & 8.14 & 1.86 & & \\
\hline \multirow{2}{*}{ Width of scar } & Single & 25 & 4.30 & 0.98 & \multirow{2}{*}{0.588} & \multirow{2}{*}{0.559} \\
\hline & $\mathrm{BM}$ & 25 & 4.14 & 0.99 & & \\
\hline \multirow{2}{*}{ Depth of scar } & Single & 25 & 3.32 & 0.86 & \multirow{2}{*}{0.064} & \multirow{2}{*}{0.949} \\
\hline & $\mathrm{BM}$ & 25 & 3.33 & 0.91 & & \\
\hline \multirow{2}{*}{ Residual myometrial thickness } & Single & 25 & 6.23 & 1.76 & \multirow{2}{*}{3.364} & \multirow{2}{*}{$0.002 * *$} \\
\hline & $\mathrm{BM}$ & 25 & 8.05 & 2.06 & & \\
\hline
\end{tabular}

Table 2: Analysis of comparison of scar parameters- 4 months.

\begin{tabular}{|c|c|c|c|c|c|c|}
\hline 4 months & Technique & $\mathbf{N}$ & Mean & SD & $\mathbf{t}$ & p \\
\hline \multirow{2}{*}{ Length of scar } & Single & 25 & 7.15 & 1.44 & \multirow{2}{*}{0.368} & \multirow{2}{*}{0.715} \\
\hline & $\mathrm{BM}$ & 25 & 7.32 & 1.77 & & \\
\hline \multirow{2}{*}{ Width of scar } & Single & 25 & 3.62 & 0.97 & \multirow{2}{*}{0.448} & \multirow{2}{*}{0.656} \\
\hline & $\mathrm{BM}$ & 25 & 3.50 & 0.92 & & \\
\hline \multirow{2}{*}{ Depth of scar } & Single & 25 & 2.72 & 0.86 & \multirow{2}{*}{0.188} & \multirow{2}{*}{0.851} \\
\hline & $\mathrm{BM}$ & 25 & 2.68 & 0.79 & & \\
\hline \multirow{2}{*}{ Residual myometrial thickness } & Single & 25 & 5.36 & 1.70 & \multirow{2}{*}{3.257} & \multirow{2}{*}{$0.002 * *$} \\
\hline & $\mathrm{BM}$ & 25 & 7.10 & 2.04 & & \\
\hline
\end{tabular}

The scar parameters measurements noted in Group B at 6 weeks were mean length $=8.14 \pm 1.86 \mathrm{~mm}$, mean width $=4.14 \pm 0.99 \mathrm{~mm}$, mean depth $=3.33 \pm 0.91 \mathrm{~mm}$. At 4 months, the values were mean length $=7.32 \pm 1.77 \mathrm{~mm}$, mean width $=3.50 \pm 0.92 \mathrm{~mm}$, mean depth $=$ $2.68 \pm 0.79 \mathrm{~mm}$. (Table 1 and 2). The mean residual myometrial thickness measured at 6week and 4 months was $8.05 \pm 2.06 \mathrm{~mm}, 7.10 \pm 2.04 \mathrm{~mm}$ respectively. The size of the scar-length, width and depth did not show statistical significance on the difference in both the groups at 6 weeks and 4 months, $p$ value $>0.05$ whereas the mean RMT value was significantly higher in Group B patients compared to Group A patients, $(\mathrm{p}=0.002)$. There was one case of scar defect (4\%) in group A.

\section{DISCUSSION}

Caesarean section is the most commonly performed abdominal surgery in a woman. It has a high rate of morbidity and mortality. The evaluation of caesarean uterotomy scar has been done by many methods in various studies to look for its link on outcome of subsequent pregnancies. The most common indication for a primary caesarean section was malpresentation in accordance with the study conducted by Glavind et al for the first elective $\mathrm{CS}^{3}$ The duration of surgery and estimated amount of blood loss was less in single continuous layer technique when compared to the other group. This is similar to studies by few authors who concluded that single layer technique requires lesser operative time and blood loss. ${ }^{4}$

However, there was no statistical difference between the two techniques in terms of operative time and blood loss. Single continuous layer technique required more additional haemostatic sutures (16\%) intra operatively similar to the description by Jelesma, Wittingen and Vander Kolk. The incidence of $\mathrm{PPH}$ and post-operative wound infection was same in both groups (4\%). According to the current evidence, single layer technique was associated with lesser operating time, intra operative 
blood loss, febrile morbidity, endomyometritis and hospitalization period. ${ }^{5}$

The advantage of TVS is the short distance between the probe and the caesarean scar region, localization of the caesarean scar and pubic symphysis and no interference by bowels and abdominal wall. 6,7

The method used by the radiologist for the assessment of scar parameters was based on the standardized technique provided by Naji, Abdallah, Bij De Vaate et al similar to the description of scar in non-pregnant uterus by Osser and Valentine. ${ }^{8,9}$ The scar maturation takes a minimum of 3 months in uncomplicated caesarean section; hence we performed a TVS at 4 months though the zonal anatomy is not completely restored.

The prevalence of scar defect in present study population was only $4 \%$ probably because we included primary caesarean section and all the cases were done elective before the patient could enter into active phase of labour. The uterus was anteverted in $66 \%$ of the cases. The only scar defect visualized was in retroverted uterus though it was not statistically significant in present study.

In a study conducted at Sweden, few authors have described more scar defects associated with retroflexed uterus. ${ }^{10}$ In the present study, residual myometrial thickness (RMT) in Babu and Magon technique at both 6 weeks and 4 months $(8.05 \mathrm{~mm} \pm 2.06$ and $7.10 \mathrm{~mm} \pm 2.04$ respectively) was superior compared to the continuous single layer $(6.23 \mathrm{~mm} \pm 1.76$ and $5.36 \mathrm{~mm} \pm 1.70$ respectively) which was statistically significant $(\mathrm{p}<0.05)$. This indicates the better healing nature of the scar with Babu and Magon technique.

The RMT value in continuous unlocked single layer in present study is higher than described by others authors (Roberge,et al, mean $=3.80 \pm 1.57 \mathrm{~mm}$, Glavind et al, mean $=4.6 \mathrm{~mm}$ ) by TVS. ${ }^{11}$ The RMT value is lower than the observed value by Sevket, Ates, Molla et al $(7.53 \mathrm{~mm} \pm 2.54)$ using hydrosonsalphingography. ${ }^{12}$ The RMT observed in Babu and Magon technique is comparable to and higher than RMT in double layer technique (Glavind et al, mean $=5.8 \mathrm{~mm}$, Roberge et al, $4.77 \mathrm{~mm} \pm 1.34$ ). To the best of our knowledge, there is no study that has evaluated Babu and Magon technique.

In a recent study, it was observed that a double layer with an unlocked first layer was associated with a greater RMT than the single layer locked technique $(\mathrm{P}<.001) .{ }^{13}$ Thus, Babu and Magon technique could be a good option for uterotomy closure in terms of good scar healing property as visualized in transvaginal ultrasonography.

The Babu and Magon technique could achieve the full thickness approximation of the cut margins that may not be possible in the conventional double layers or single layer method due to the nature of the lower segment. Hence, we conclude that the RMT was higher in Babu and Magon uterine closure group that could result in better scar healing and also might reduce the adverse outcomes in subsequent pregnancies.

The study was conducted in a small sample size, so these findings could not be extrapolated to a large population of various populations. Further research regarding to follow up these women in their next pregnancies and assess the chance of vaginal delivery or assess the scar thickness at surgery is also needed.

\section{Funding: No funding sources}

Conflict of interest: None declared

Ethical approval: The study was approved by the Institutional Ethics Committee

\section{REFERENCES}

1. Hofmeyr GJ, Mathai M, Shah A, Novikova N. Techniques for caesarean section. Cochrane Database Syst Rev. 2008;1:CD004662.

2. Babu K, Magon N. Uterine closure in cesarean delivery: a new technique. N Am J Med Sci. 2012;4:358-61.

3. Glavind J, Madsen LD, Uldbjerg N, Dueholm M. Ultrasound evaluation of Cesarean scar after single- and double-layer uterotomy closure: a cohort study. Ultrasound Obstet Gynecol. 2013;42:207-12.

4. Dodd JM, Anderson ER, Gates S, Grivell RM. Surgical techniques for uterine incision and uterine closure at the time of caesarean section. Cochrane Database Syst Rev. 2014:CD004732.

5. Hegde CV. The never-ending debate single-layer versus double-layer closure of the uterine incision at cesarean section. J Obstet Gynaecol India. 2014;64:239-40.

6. Jelsema RD, Wittingen JA, Vander Kolk KJ. Continuous, nonlocking, single-layer repair of the low transverse uterine incision. J Reprod Med. 1993;38:3936.

7. Pomorski M, Fuchs T, Zimmer M. Prediction of uterine dehiscence using ultrasonographic parameters of cesarean section scar in the nonpregnant uterus: a prospective observational study. BMC Pregnancy Childbirth. 2014;14:365

8. Naji O, Abdallah Y, Bij De Vaate AJ, Smith A, Pexsters A, Stalder C, et al. Standardized approach for imaging and measuring Cesarean section scars using ultrasonography. Ultrasound Obstet Gynecol. 2012;39:252-9.

9. Osser OV, Valentin L. Clinical importance of appearance of cesarean hysterotomy scar at transvaginal ultrasonography in nonpregnant women. Obstet Gynecol. 2011;117:525-32.

10. Osser OV, Jokubkiene L, Valentin L. High prevalence of defects in Cesarean section scars at transvaginal ultrasound examination. Ultrasound Obstet Gynecol. 2009;34:90-7.

11. Roberge S, Demers S, Girard M, Vikhareva O, Markey $\mathrm{S}$, Chaillet $\mathrm{N}$, et al. Impact of uterine closure on residual myometrial thickness after cesarean: a randomized controlled trial. Am J Obstet Gynecol. 2016;507:e1- e6. 
12. Sevket O, Ates S, Molla T, Ozkal F, Uysal O, Dansuk R. Hydrosonographic assessment of the effects of 2 different suturing techniques on healing of the uterine scar after cesarean delivery. Int $\mathbf{J}$ Gynaecol Obstet. 2014;125:219-22.

13. Roberge S, Boutin A, Chaillet N, Moore L, Jastrow N, Demers $\mathrm{S}$, et al. Systematic review of cesarean scar assessment in the nonpregnant state: imaging techniques and uterine scar defect. Am J Perinatol. 2012;29:465-71.

Cite this article as: Vinayachandran S, Sudhakar V. Comparison of two different techniques of uterine closure in caesarean section: continuous single layer technique versus BABU and MAGON technique. Int J Reprod Contracept Obstet Gynecol 2018;7:2197201. 